\title{
Os Primeiros Trinta anos da Revolução Cubana à luz do Pensamento Martiano
}

\section{Introdução}

A motivação que originou esta proposta de análise dos primeiros trinta anos da Revolução cubana sob a orientação do pensamento martiano surgiu após a identificação de algumas diretrizes políticas deste período cuja influência não está explicitamente assentada no socialismo de inspiração marxiana, nas experiências de socialismo real e nem mesmo nos caminhos trilhados por outras nações latino-americanas em busca de soberania nacional. Para compreender como a Revolução Cubana tratou de alguns aspectos relacionados ao atrasado desenvolvimento socioeconômico nacional, como no caso das questões urbana, agrária e racial, foi necessário recorrer a Martí. Dentre os exemplos considerados, creditamos ao pensamento martiano a decisão política da distribuição pessoal do parque habitacional de forma privada durante a Reforma Urbana, a distribuição de pequenas terras agrícolas individuais aos trabalhadores rurais e a precoce preocupação do governo revolucionário com o preconceito racial.

\footnotetext{
${ }^{1}$ Mestrando em Economia pela Universidade Estadual de Campinas (UNICAMP), elaborando a dissertação "O sistema socioeconômico cubano e suas transformações (1959 - 2017)”. Contato: filipefarhat @ gmail.com ${ }^{2}$ Mestre pela Universidade Estadual Paulista Júlio de Mesquita (UNESP) e doutoranda em Desenvolvimento Econômico pela Universidade Estadual de Campinas (UNICAMP) com o tema "O papel da moradia no modelo de transição ao socialismo cubano: contribuições a partir de Havana”. Contato: alinemmiglioli @ gmail.com.

${ }^{3}$ Mestre e Doutor em Desenvolvimento Econômico e História Econômica e atualmente professor e pesquisador do Instituto de Economia da Universidade Estadual de Campinas (UNICAMP). Principais temas de estudo são a transição do feudalismo ao capitalismo, o sistema colonial, a formação econômica do Brasil, o imperialismo e o pensamento brasileiro. Contato: cordovanovieira@ yahoo.com.br
} 
As propostas elaboradas por Martí em resposta aos problemas do período colonial não se subscreviam somente a ele. A preocupação com as dificuldades estruturais da formação nacional cubana fez de Martí um dos maiores intérpretes desta sociedade e permitiu que suas formulações teóricas continuassem influenciando na construção da sociedade cubana até os dias atuais.

Apesar da explícita influência de Martí nas formulações políticas do Partido Comunista Cubano (PCC), dentre autores que avaliam a produção científica em Cuba ao longo das décadas de 1960 a 1980 se reconhece que houve um esvanecimento da influência da tradição martiana no pensamento social cubano (Acanda, 2013; Arnal, 2014; Treto, 2005; Martín, 1999). Segundo estas análises é possível dividir a produção científica pós revolucionária em três fases. Nos anos 1960 constata-se uma explosão da produção científica da ilha, encorajada pelas transformações sociais pós-revolucionárias e pela aplicação de uma política de educação pública ativa, que promoveu a Reforma Universitária e o fim do analfabetismo. Durante este período, boa parte dos acadêmicos não alinhados à ideologia socialista havia deixado o país, suscitando a necessidade de formação de novos quadros, os quais foram formados neste cenário de ecletismo e liberdade acadêmico. Verifica-se, a partir de então, um experimentalismo das produções científicas, pautadas pelo diálogo entre o campo do marxismo ocidental, o marxismo crítico latino-americano e as instituições regionais de pesquisa como a CEPAL, o ILPES, a CELADE e a FLACSO 4 (Martín, 1999).

A divergência entre os adeptos do marxismo ocidental, formulado nos países centrais, e o marxismo de tradição cubana havia se forjado ainda durante a década de 30, como reflexo da própria cisão do Partido Comunista Cubano através das disputas relacionadas às práticas políticas adotadas em Cuba e o apoio às políticas de Moscou ${ }^{5}$. Porém entre os anos 1970 e 1985, a aproximação com a União Soviética e a consolidação e desenvolvimento das instituições socialistas alteraram o cenário acadêmico em Cuba e a correlação de forças entre as vertentes de teorias analíticas socialistas. No campo das ciências sociais houve um

\footnotetext{
${ }^{4}$ Respectivamente Comissão Econômica Para América Latina e o Caribe, Instituto Latino Americano de Planificação Econômica e Social, Centro Latino Americano de Desenvolvimento e Faculdade Latino Americana de Ciências Sociais.

${ }^{5}$ A cisão entre os membros do Partido Comunista Cubano (que mudou de nome para Partido Socialista Popular após voltar à legalidade em 1939) refletia a divergência sobre três pontos: a estratégia a implementar-se em Cuba para lograr a Revolução, dividindo o partido entre aqueles que restringiam a participação do partido aos movimentos urbanos; a "obediência" às diretrizes do Komitern, que se acentuaram após o acordo entre Moscou e o governo nazista em 1939; e internamente, sobre o aceno do partido à negociar o candidato presidencial proestadunidense, Fulgêncio Batista (Acanda, 2013).
} 
esvaziamento generalizado, pois, esta área de pesquisa deixou de existir como matéria universitária e foi substituída pela disciplina de Materialismo Dialético. Prevaleceu o marxismo de tradição ocidental na produção científica, como resultado da aproximação econômica à URSS e ao CAME, das cooperações acadêmicas com outros países socialistas e da publicação em Cuba do Editorial Progresso (da antiga URSS) dos manuais soviéticos para educação marxista em massa (Sandoval; Hernandes, 2002; Martín, 1999). Neste período o PCC orientou explicitamente as pesquisas a restringirem-se ao campo da teoria marxistaleninista, as quais eram produzidas e utilizadas dentro das instituições de ensino e governo. Desta forma, apesar da fundação do Centro de Estudos Martianos em 1977, pouco existe de produção científica sobre o pensamento martiano nesta década, quando comparado à produção científica marxista-leninista e aos trabalhos que buscam interconexões entre ambos autores (Barreras et al. 2018).

A aparência destes eventos, pode levarmos a crer que existiu nestes primeiros trinta anos de Revolução um afastamento entre o pensamento martiano e a formulação e execução das políticas em Cuba. Nossa proposta para este trabalho é demonstrar a permanência das influências do pensamento martiano nos primeiros trinta anos da Revolução Cubana. Para tanto, vamos recorrer às principais políticas e decisões tomadas durante este período, evidenciando em que ponto elas se aproximam do pensamento de José Martí ou são guiadas por outras influências, em especial do marxismo. Escolheu-se por restringir o escopo deste artigo aos trinta primeiros anos da Revolução, pois o fim da URSS no final da década de 1980, o acirramento do bloqueio norte-americano e a consequente crise econômica pela qual passou Cuba resultaram em determinado contexto geopolítico e social de mais complexa análise, tanto no âmbito doméstico quanto nas relações internacionais, no qual as orientações políticas estiveram direcionadas a garantir as conquistas sociais possibilitadas pelo projeto revolucionário. Neste sentido, aplicou-se, a partir de então, o que ficou denominado pelas lideranças revolucionárias como retificação de erros, na qual se revisaram criticamente as diretrizes políticas e o embasamento teórico da trajetória que vinha sendo perseguida. $\mathrm{O}$ período subsequente, o período especial, é marcado por uma intensa crise econômica e pelo desaparecimento do bloco socialista. Neste momento se inicia a busca pela sobrevivência material, pela manutenção do processo revolucionário e pela soberania nacional, o que recoloca o pensamento martiano de uma outra perspectiva. Não seguiremos por este período, pois o próprio desaparecimento do bloco soviético esvazia o problema a qual refere-se este 
artigo. Insistimos em delimitar a análise deste artigo aos trinta primeiros anos de Revolução, e principalmente aos dez primeiros anos, pois durante este período houve a possibilidade de grandes experimentações, disputa de ideias e tensões entre o modelo socialista inspirado na experiência soviética e construções sociais baseadas em contribuições locais, como no episódio do Grande Debate do final dos anos 1960.

Sem dúvidas, a abordagem que queremos seguir pode incorrer no anacronismo de avaliar um período histórico específico a partir de propostas formuladas para outra problemática. Reconhecemos Martí como personagem do processo revolucionário que culminou em 1959, porém também entendemos que muitas de suas formulações somente podem ser interpretadas no contexto de transição da fase capitalista de pequenos empreendimentos ao capitalismo monopolista, ou seja, no período histórico que caracterizou o fim do período colonial cubano. No entanto, o modelo de sociedade que concebe e o sujeito que a compõe são traços que permitem que seu pensamento transcenda aquela especificidade histórica. Outro desafio se relaciona a precisar com exatidão posicionamentos ideológicos nas esferas política e econômica de um autor cuja obra evoluiu e se modificou ao longo de sua trajetória e foi publicada na forma de reportagens, artigos, novelas e poemas. O que faremos, portanto, é identificar em quais momentos e sob quais condições as lideranças revolucionárias buscaram o aporte teórico martiano para a condução de suas políticas, o que significa identificar em qual momento foi necessário recorrer às discussões relativas à formação nacional soberana, para a construção do socialismo em Cuba.

Para alcançar o objetivo proposto neste artigo iremos dividir o trabalho em três partes para além desta pequena introdução. Na primeira, vamos recuperar alguns traços do pensamento martiano escolhidos para avaliar os trinta primeiros anos de revolução. Em seguida, apresentaremos as principais influências do pensamento martiano na formulação das principais políticas elaboradas neste período, a Reforma Agrária, a Reforma Urbana e o Primeiro Plano Econômico, até a Retificação de Erros em 1986, e, por fim, teceremos algumas considerações finais.

\section{José Martí e os Principais Fundamentos Teóricos de uma Política Soberana}

José Martí nasceu em Cuba em 1853. Filho de espanhóis emigrados, não provinha de uma família abastada. Sua educação formal foi promovida graças a seu professor do ginásio, 
Rafael Maria de Mendive, cuja orientação o colocou em contato com o pensamento cubano revolucionário, independentista e liberal. Durante sua breve vida, Martí lutou e combateu nas guerras pela independência de Cuba: a Guerra dos 10 anos (1868 - 1878), a Guerra Chiquita (1879 - 1880) e ajudou a organizar a Guerra Necessária (1895-1898), na qual foi morto em combate em 1885 com 42 anos. Estas três guerras relacionam-se com a questão independentista em Cuba. A guerra dos 10 anos se caracterizou pelo o primeiro levante organizado entre os colonos, principalmente da região do ocidente de Cuba, contra o domínio colonial espanhol, incomodados com o fato de que apesar de apenas $8 \%$ da população na ilha ser de origem espanhola naquele período, a metrópole se apropriava de $90 \%$ dos lucros gerados no país. Ademais, o excesso de impostos e as restrições às liberdades individuais resultaram na união dos profissionais liberais, intelectuais e escravos no levante. $\mathrm{O}$ movimento libertador tomou as regiões de Bayamo, Camaguey e Las Villas, regiões centrais e orientais da ilha, porém não conseguiu o apoio do ocidente, fiel à coroa espanhola. A divergência sobre a estratégia de luta pelo movimento libertador, entre aqueles propensos a ação unificada e aos partidários da atuação de colunas descentralizadas, e o massacre violento da coroa espanhola interromperam o processo revolucionário, tendo como saldo positivo da conquista da abolição da escravidão. A tentativa de manter o levante independentista um ano depois da derrota de 1878 recebeu o nome de Guerra Chiquita e consistiu na tomada de poder do Ocidente e do Centro pelo movimento libertador. No entanto, a estratégia de ocupação contava com a chegada de armamentos e lideranças articuladas do exterior, os quais foram interpelados pela Espanha. José Martí, em uma avaliação crítica de como se havia atuado nos dois levantes anteriores, organizou e difundiu o projeto de revolução independentista a partir da atuação do Partido Revolucionário Cubano, composto por exilados, "criollos", trabalhadores e escravos libertos unidos pela bandeira da emancipação nacional. Desta forma, Martí articulou os fundamentos do processo revolucionário vitorioso iniciado em 1895 (Navarro, 2000). Neste intervalo, foi preso em Cuba duas vezes e, devido à possibilidade de comutação de sua pena, viveu exilado na Espanha, México, Guatemala, Venezuela e Estados Unidos, de maneira que suas experiências nestes países influenciaram suas formulações teóricas e suas práticas políticas. Martí, além das inúmeras publicações em seu nome e dos cargos políticos que ocupou como embaixador, fundou o Partido Revolucionário Cubano.

Durante sua formação escolar em Cuba, Martí esteve em contato através de seu tutor com a tradição de pensamento sociológico cubano de matriz independentista e orientada à 
formação pesquisa científica autônoma, de uma filosofia nacional cubana, como Feliz Varela, José A. de la Luz y Cabellero e o próprio Rafale Mendive. Porém, foi apenas durante seus anos no exílio espanhol que Martí desenvolveu um traço que acompanharia toda a sua produção teórica: a enorme crença nas virtudes do homem. Influenciado também pelo liberalismo que despontava na Europa, desenvolveu fiel convicção nos ideais revolucionários franceses de liberdade, igualdade e fraternidade, adaptando-os para a realidade que encontrava na América Latina (Suchlicki, 1966). É a partir deste contexto que o centro da teoria martiana se arraiga nos valores de liberdade e justiça. A liberdade, entendida como a garantia aos direitos individuais e ao respeito mútuo para todos os grupos sociais e "raças", é, para o autor, o principal desejo do homem. Martí distingue a relação do homem com este desejo, separando-o em dois grupos de comportamento: aqueles que amam a liberdade porque a querem somente para si, e para isso cerceiam a liberdade dos outros, e aqueles que a amam e a querem para todos. Caberiam a estes últimos lutar e exigir liberdade a todo momento que a encontrarem ameaçadas pelos primeiros. Martí não distinguia a liberdade individual da liberdade social, e muito por influência dos pensadores norte-americanos liberais com os quais teve contato $^{7}$, admitia que a busca pela liberdade individual resultaria na liberdade social, ou seja, que o bem individual levaria ao bem social, e, portanto, não seria admissível que para buscar o máximo bem do ponto de vista da sociedade em geral se tolerasse ônus individuais. Estes pressupostos lhe foram úteis para defender sua visão de democracia, assim como para rejeitar e combater o discurso da inferioridade de raças, dominante no pensamento científico da época e ancorado no darwinismo de Spencer (Santos, 2011). Para que existisse justiça social, no entanto, não se faria suficiente garantir o direito à liberdade. No pensamento martiano, democracia e equilíbrio de forças são outros requisitos chave para atingir tal objetivo.

A ideia de equilíbrio de forças também está presente na interpretação de Martí sobre a política internacional. Observando o interesse norte-americano em Cuba, ele prontamente percebe que reside neste contato uma relação desigual, que se refletia no interesse ianque em

\footnotetext{
${ }^{6}$ Martí rejeita a existência de raças humanas. Precocemente ele reconhece que o discurso de raças serviria para inferiorizar e submeter um homem ao outro, perpetuando o sentido da escravidão mesmo depois da sua abolição. Durante as guerras que participou, Martí percebeu que, o interesse em comum pela independência de Cuba tinha o poder de aproximar brancos e negros e fazia desaparecer as supostas diferenças entre raças. Martí advogava, portanto, que na formação do cubano, não cabia espaço para as distinções de cor de pele, origem etc. (Martí, 1893).

${ }^{7}$ No momento em que esteve nos EUA e na França, Martí esteve inspirado pelas palavras de ordem da Revolução Francesa e pelos escritos de John Locke, Spencer etc.
} 
anexar a ilha ao território estadunidense, assim como ocorrido com Porto Rico. Martí identifica e rejeita, portanto, as práticas imperialistas norte-americanas, ao reconhecer que estas, ao encorajarem a disputas entre projetos políticos distintos, como ocorria em Cuba entre os cubanos anexionistas e independentistas, incitavam o divisionismo no país. Para Martí, o imperialismo representava, sobretudo, um obstáculo para a construção de uma sociedade baseada no amor. É a partir deste referencial teórico que passa a encarar e estudar a sociedade cubana e mais à frente a América Latina ${ }^{8}$.

Cabe ressaltar, contudo, que em seus escritos não havia qualquer defesa de isolacionismo ou de restringir os contatos internacionais no âmbito econômico bem como em outras questões. O projeto de emancipação martiano passava por um ideal de uma ordem internacional baseada na cooperação entre os povos e na igualdade de poder entre as relações mundiais travadas entre diferentes nações.

Ao tratar da América Latina, Martí dialoga diretamente com a ideologia burguesa europeia em voga naquele período, na qual as opções de futuro para a região recaíam ou na barbárie, reflexo da permanência do estado "natural" dos povos nativos, ou na civilização, como metonímia do estado de desenvolvimento da Europa. O homem nativo, segundo a tradição científica eurocêntrica, era um ser inferior ao branco-europeu, e que, portanto, deveria ser extinguido a partir de seu enquadramento neste modelo civilizatório. Contornando esta chave dicotômica, Martí reconhecia que este projeto de "modernização" resultaria na imposição de uma identidade alheia ao povo latino-americano como justificativa para inúmeras práticas de dominação e dependência (Júnior, 2007). A solução proposta pelo autor, é a da recuperação do homem natural e de toda sua cultura para a formação da nova identidade nacional. Apesar do termo "homem natural" remeter à ideia de homem primitivo, aborígene ou selvagem, este conceito trata do homem que consegue recuperar sua relação orgânica com a natureza, seja através de sua religião, da arte ou da ciência, libertando-se da cosmovisão do homem moderno europeu. Para Martí, a luta pela independência só pode ser feita pelo homem natural, portanto, ele é o sujeito desta luta. Ao mesmo tempo, somente com a independência da nação se poderão desenvolver todas as potencialidades deste indivíduo, portanto ele é também o objetivo, o fim, a razão de ser da luta pela emancipação nacional.

\footnotetext{
${ }^{8} \mathrm{O}$ conceito de América Latina como a América de origem portuguesa e espanhola foi cunhado e popularizado posteriormente. Martí utilizou o termo Nuestra América, que compreendia como todas as formações que não se identificavam com a América Inglesa, notadamente, as 13 colônias, ou a América acima do Rio Bravo.
} 
O que justifica a escolha desse sujeito histórico é a avaliação de que a chegada da empresa colonial interrompeu o desenvolvimento do povo nativo e criou, a partir da mescla com a cultura europeia, um novo povo. Este, para Martí, deteria os conhecimentos e as soluções para realizar-se como povo, para tanto, não poderia se deixar obstaculizar uma vez mais pela influência dos colonizadores. É neste sentido que a proposta martiana tem caráter autóctone, pois deposita no próprio sujeito latino-americano e em seus saberes, valores e práticas a responsabilidade de construção de uma nova sociedade. Novamente, diferentemente do sujeito europeu, este sujeito latino-americano tinha a possibilidade de construir uma sociabilidade baseada no amor.

Em suma, a proposta de Martí é de que, para a construção de uma sociedade baseada no amor, era preciso formar a identidade própria da américa-latina, a qual tinha, em cada país, uma particularidade. Para isso, era preciso resgatar o homem natural, cujo desenvolvimento havia sido interrompido pela empresa colonial e acabar com as relações impostas por este sistema. Esta proposta tinha como obstáculo a tentativa de suplantação de outras formas políticas, econômicas e culturais "alheias" através da intervenção de outros países na conformação da identidade latino-americana e da ameaça ao seu processo de construção autônomo.

A sua defesa da formação do homem natural e da autonomia nacional não significava a interrupção das relações políticas e comerciais com outros países, desde que guiadas por um equilíbrio de poderes. Desta feita, em termos de projeto econômico, Martí defendia o livre comércio como princípio garantidor da liberdade e do equilíbrio de forças. Contudo, assumia que existiam diferenças de poder entre quem compra e quem vende e avaliava com muita cautela e preocupação os acordos comerciais realizados entre Cuba e Estados Unidos. Esta discussão se insere no âmbito mais geral do expansionismo estadunidense, de maneira que a defesa de Martí pela efetiva independência e soberania de Cuba seria condição necessária para o desenvolvimento de um padrão civilizatório latino-americano crítico àquele predominante no Ocidente. Desta feita, a noção de equilíbrio del mundo ${ }^{9}$ no pensamento martiano complementa e extrapola sua visão sobre o homem natural para o domínio da geopolítica, sendo um dos principais pontos de seu sistema filosófico. Para o desenvolvimento de todas as potencialidades do indivíduo cubano (latino-americano) e do forjamento de uma sociedade

\footnotetext{
${ }^{9}$ Para uma discussão mais aprofundada do significado de equilibrio del mundo no sistema filosófico martiano, ver Santos (2011).
} 
autóctone no continente, deveria ser prestada especial atenção aos desdobramentos das relações internacionais em todo o globo, de maneira que estas permitissem a busca pelos valores sociais perseguidos em esfera nacional e continental.

As contribuições teóricas de Martí estão presentes nas orientações práticas de seu programa político para Cuba. Suas formulações incidiram principalmente na busca de solução à questão da liberdade, compreendida como a liberdade de Cuba existir como um país soberano e na igualdade individual independentemente da "raça", termo que Martí achava inadequado do ponto de vista conceitual. Para criar e sustentar esta tal sociedade livre e independente, ele via como fundamental a formação de um cenário político e econômico que permitisse o desenvolvimento do homem natural, o qual ele supunha que estivesse ligado à terra de forma autônoma e que pudesse exercer seus credos e sua "ciência" de forma livre. De maneira sintética, o programa político que se desdobrou destes apontamentos pressupunha a pequena propriedade rural e os salários justos, ambas condições para realização do homem natural, e a democracia como forma de garantia das liberdades. A resposta de Martí, no contexto da economia cubana do final do século XIX, para garantir o equilíbrio de poder econômico na ilha, era a formação de uma sociedade agrícola de pequenos produtores, a qual resultaria em um modelo econômico baseado na indústria de bens naturais, no livre comércio internacional e na diversificação da produção agrícola. O pequeno produtor é a resposta martiana ao desequilíbrio de poder evidenciado pela existência da concentração fundiária. Não há em seu projeto econômico menção à necessidade de industrialização ou substituição de importações, mas acompanhando o raciocínio de Martí, é possível supor que, se tivesse escrito em momento histórico posterior, provavelmente o autor aludiria à industrialização como possibilidade de emancipação da sociedade cubana.

A distribuição do poder econômico é tema nevrálgico ao pensamento de Martí, o que o fez criticar a existência de grandes trusts e monopólios em suas análises da economia dos Estados Unidos. Neste mesmos escritos, evidencia-se que Martí reconhecia os efeitos destas formas de organização para a vida dos trabalhadores. Neste aspecto, pelo fato da obra marxiana publicada naquele período pouco tratar do problema da emancipação nacional das colônias e países de desenvolvimento econômico tardio e por se centrar em aspectos melhor evidenciados no núcleo capitalista, as contribuições originais de Martí complementam a proposta de socialismo marxiano e ajudam a trilhar a construção de uma sociedade soberana e revolucionária na América Latina. Sua crença no equilíbrio de poder e na democracia como 
valores fundamentais o levou a defender a aliança entre setores econômicos da população nacional como forma de barrar as ameaças estrangeiras e construir a nova nação.

A partir desta caracterização mais ampla do pensamento martiano, que não se esgota aqui, seguiremos aprofundando em alguns pontos específicos que dialogam diretamente com os primeiros trinta anos de governo revolucionário, seja como fonte de inspiração teórica, seja como argumento para a crítica.

\section{Desdobramentos da Revolução Cubana à luz do Pensamento Martiano: 1959-1989}

As primeiras medidas adotadas pelo Governo Revolucionário foram orientadas pelas indicações de três documentos: o Programa Moncada, nome pelo qual ficaram conhecidos os apontamentos de Fidel contidos em seu discurso de autodefesa em 1954 sobre as principais necessidades de Cuba (Castro Ruz, 1964), a Primeira e a Segunda Declaração de Havana, discursos proferidos por Fidel em 1960 e 1962, respectivamente (Castro Ruz, 2018).

\footnotetext{
"En nuestros países se juntan las circunstancias de una industria subdesarrollada con un régimen agrario de carácter feudal. Es por eso que con todo lo dura que son las condiciones de vida de los obreros urbanos, la población rural vive aún en más horribles condiciones de opresión y explotación; pero es también, salvo excepciones, el sector absolutamente mayoritario en proporciones que a veces sobrepasa el $70 \%$ de las poblaciones latinoamericanas" (Castro Ruz, 1964).
}

Em seu discurso de autodefesa conhecido como "A história me absolverá", Fidel (1993) elencou seis pontos que considerava nevrálgicos à transformação da sociedade cubana, são eles: o problema da terra, da industrialização, da moradia, do desemprego, da educação e da saúde do povo. Neste mesmo texto, ele sugeriu algumas medidas necessárias para acabar com os problemas nestas seis áreas. No que compete à terra, reconheceu a importância da atividade agrícola para o país e propôs as seguintes medidas para acabar com a pobreza resultante de sua concentração e internacionalização da propriedade: o assentamento com caráter de propriedade aos 100 mil agricultores pequenos que pagavam pelo arrendamento da terra, o estabelecimento de um limite de extensão da propriedade da terra, a reivindicação e expropriação das terras usurpadas durante a intervenção norte-americana e na ditadura Batista e a divisão das terras restantes às famílias cubanas, fomentando o cooperativismo e facilitando o acesso à recursos, equipamentos, proteção, conhecimento etc. (Castro, 1964). Da mesma maneira que observou o problema da estrutura de propriedade de terras vigente como um dos 
mais perniciosos para o trabalhador rural naquele momento, deu especial atenção aos efeitos prejudiciais ocasionados pelos elevados aluguéis a que era submetido o trabalhador urbano. A solução sugerida, ainda neste mesmo texto, valia-se do rebaixamento em $50 \%$ dos preços dos aluguéis, da cobrança triplicada dos impostos fundiários para aqueles que tinham casas de aluguel, a liberação de pagamento de impostos para aqueles que habitavam suas casas próprias e, por fim, o financiamento da construção de habitações por parte do Estado.

Estas primeiras resoluções objetam dar condições de desenvolvimento pessoal e profissional ao trabalhador cubano, tanto rural quanto urbano. As considerações de Fidel sobre a importância do estabelecimento dessas relações estáveis revelam a influência do homem natural proposto por Martí, que encontrava na pequena propriedade individual o caminho para sua autorrealização. Cabe notar que tais proposições, condizentes com os ideais de Martí, vão ocasionando profundas transformações nas estruturas sociais, econômicas, políticas e culturais cubanas, à medida em que começam a se explicitar as contradições entre as bases materiais herdadas da dominação neocolonial americana e a reorganização da sociedade desdobrada dos acontecimentos revolucionários e, portanto, vão sofrendo alterações aproximam a Revolução à trajetória socialista.

A estrutura econômica baseada na exploração do trabalho no campo e nas cidades teve como consequência a rápida promulgação da Lei de Reforma Agrária e da Reforma Urbana, seguidas da elaboração do Primeiro Plano Econômico em Cuba. Exploraremos a seguir os fundamentos que ratificaram estas três leis e como elas foram alterando-se ao longo dos primeiros trinta anos da Revolução Cubana.

A Reforma Agrária Cubana foi implementada em duas fases, através da primeira e da segunda lei da reforma agrária. A urgência em sua elaboração resultava da importância do setor para a organização da economia cubana: a produção agrícola nos anos 1950 era a atividade de maior participação relativa no PIB do país e nela se reproduzia socialmente um trabalho de baixa remuneração que impossibilitava o adequado desenvolvimento material da população camponesa. Por isso, o enfrentamento da questão agrária se fazia fundamental após o sucesso da tomada revolucionária do poder do país no início de 1959, para efetiva e significativa reestruturação de suas forças produtivas. A Primeira Lei de Reforma Agrária foi promulgada em 1959 objetivando extinguir a propriedade latifundiária e dotar o pequeno agricultor (assalariado, arrendatário, subarrendatário) da posse da terra onde exercia seu trabalho. Esta medida, assim como a maioria daquelas implantadas nos primeiros anos pós 
Revolução, foi fortemente influenciada pela visão martiana de justiça e desenvolvimento social. (Páz, 2011)

$\mathrm{Na}$ apresentação de sua defesa durante o julgamento do ataque ao quartel Moncada em 1953, Fidel Castro deixa patente que a construção da nova sociedade cubana, caso as lutas guerrilheiras obtivessem sucesso na destituição da ditadura de Fulgêncio Batista, teria por principal inspiração o pensamento de José Martí (Castro Ruz, 1964). Assim, a reestruturação da propriedade agrícola foi condizente com a aversão de Martí à consolidação da etapa monopolista do capitalismo presenciada por ele no período em que viveu nos EUA. Buscavase, ao extinguir a propriedade privada latifundiária, acabar com a forma de dominação e subordinação econômica e social do trabalhador rural ao detentor do capital. A organização da terra cultivada em pequenas propriedades privadas pertencentes à população camponesa, além de ampliar substancialmente a liberdade daqueles beneficiados por tal reforma, ainda garantiria maior segurança alimentar ao país. Portanto, melhorava-se o padrão de vida material da população mais pobre, ao mesmo tempo em que se ampliava a efetiva soberania nacional, ao garantir que a produção agrícola do país estivesse guiada pelos interesses domésticos. Esta preocupação com o aumento da soberania e a independência concreta de Cuba, incorpora fortemente o espírito da militância política de Martí, que chamou atenção em seus escritos e discursos para o caráter neocolonial de dominância americana que começava a se configurar na sociedade cubana em fins do século XIX.

Concluída a primeira etapa de reorganização da propriedade agrária cubana, que teve como objetivo primordial o combate ao domínio neocolonial americano da estrutura de produção agropecuária (especialmente açucareira) do país, gradualmente as lideranças revolucionárias passaram a deslocar o foco das políticas para estratégias de desenvolvimento de longo prazo.

Para tanto, após alguns anos em que a sociedade cubana pôde realizar experiências em que conviveram conjuntamente a posse de terra individual do pequeno agricultor, a organização cooperativa, as Granjas do Povo (administradas diretamente pelo Partido Comunista) e os lotes de médio e grande porte dirigidos por capitalistas estrangeiros e nacionais (ainda que as gigantes propriedades latifundiárias tivessem sido extintas), o governo decretou a Segunda Lei da Reforma Agrária (Molina, 2016). Nela, ficou estabelecida a nacionalização de toda terra previamente administrada pela classe capitalista doméstica e externa e a condenação da organização cooperativa da propriedade agrária. Se, por um lado, o 
debate entre a melhor forma de produção entre as cooperativas e a administração estatal se deu em função de aspectos técnicos do setor - e continua vivo hoje -, por outro, a apropriação e nacionalização da terra pelo Estado se deu, principalmente, pelo reconhecimento da impossibilidade prática de se manter um regime de aliança de classes em Cuba na primeira metade dos anos 1960 (Rodriguez, 1990).

Assim, vai se tornando patente a necessidade de radicalização da Revolução para a manutenção de suas conquistas, dada a disputa aberta, e mesmo violenta, com os representantes do capital norte-americano imperialista e com a subordinada classe capitalista doméstica. A imposição das forças históricas particulares daquele período e sua interação com as características da formação e evolução socioeconômica de Cuba levou a Revolução aos desdobramentos ocorridos.

Esta reorientação política deu-se em resposta aos fatos sucedidos nos anos de vigência da Primeira Lei de Reforma Agrária, durante os quais a acumulação de capital em terras privadas havia sido utilizada para dar suporte à luta contrarrevolucionária, minando qualquer possibilidade de um regime democrático popular dentro da institucionalidade capitalista vigente, ao menos no que diz respeito ao setor agrário. Assim, ainda que se tenha buscado seguir o ideal martiano de respeito ao livre desenvolvimento das potencialidades de todos os indivíduos no âmbito econômico, a necessidade de desenvolvimento das forças produtivas nacionais e de enfrentamento do domínio do capital estrangeiro associado a setores da burguesia cubana explicitou as necessidades da implantação de medidas políticas de maior controle social dentro do processo revolucionário. Não significa dizer que as lideranças tenham se afastado da idealização social martiana e se aproximado exclusivamente do pensamento socialista marxiano. Mas que, novamente, a necessidade de radicalização ficava patente para dar prosseguimento à construção de uma sociedade substantivamente democrática e popular, dada a situação em que se encontrava Cuba em suas relações globais naquele momento histórico.

Contudo, tal medida não poderia proporcionar o avanço da produtividade agrícola necessário ao atingimento de um nível de desenvolvimento econômico que viabilizasse a soberania nacional de Cuba sob o modo de produção capitalista, ainda que a influência dos princípios liberais martianos na construção deste processo histórico possibilitasse significativa melhoria do padrão de vida da maior parte da população. Neste sentido, a Revolução Cubana e suas lideranças, desde os primeiros anos após a destituição do governo Batista, buscaram 
encontrar soluções originais para a emancipação nacional e individual, que desembocaram na necessidade de romper com o modo de produção vigente. É neste sentido que ainda que tenha permanecido o foco nas lutas pela efetiva soberania nacional, o pensamento martiano, no período em tela, vai sendo acompanhado pelo fortalecimento da trajetória socialista.

O governo cubano reorientou a estratégia produtiva nacional e buscou diversificar a produção agrícola para que o país pudesse reduzir a importação de alimentos, iniciando, gradualmente, um processo de substituição de importações que permitiria atingir a soberania e uma relação de igualdade de poder nas negociações internacionais. Esta estratégia pode ser avaliada positivamente à luz do pensamento martiano, ao propor-se um reencontro com o equilíbrio produtivo e um retorno às práticas de produção que aproximassem o homem da terra, como advogava Martí. Contudo, equívocos no planejamento econômico e de sua execução pelo governo cubano resultaram em redução da produção açucareira em termos absolutos (ao invés de apenas relativos), e, dado que esta era a principal mercadoria geradora de divisas, surgiram graves restrições ao desenvolvimento econômico do país impostos pelos resultados da balança comercial. Em consequência, ocorreu a necessidade do retorno da especialização produtiva e da ênfase na exportação de açúcar, agora circunscrito à nova posição de Cuba na divisão internacional do trabalho no bloco socialista. (Cano, 2000)

A Reforma Urbana perseguia os mesmos objetivos e tinha a mesma importância política que a Reforma Agrária, de maneira que constituiu também uma das prioridades do governo após a Revolução. O problema urbano em Cuba neste período explicitava-se no exorbitante valor dos aluguéis e na dificuldade para aquisição de casa própria pelo trabalhador urbano, o que resultava em habitações precárias, superpopulosas e em péssimas condições dos serviços urbanos. Os trabalhadores urbanos eram antigos trabalhadores rurais que buscavam nas cidades formas de garantir melhores condições de vida, mas que encontravam nelas poucos empregos e com baixa remuneração. A possibilidade de moradia que se colocava para esta classe era o aluguel de quartos ou de pequenas moradias pertencentes à burguesia cubana e está, como estava pouco envolvida em outras atividades econômicas, fazia do rentismo sua principal fonte de renda, a qual era protegida pelo arcabouço institucional que facilitava os despejos e desalojamentos voluntários, sem resguardar nem proteger os inquilinos.

A Reforma Urbana, portanto, foi um conjunto de medidas com objetivo de acabar com a especulação imobiliária e com o rentismo. As três primeiras medidas, tomadas ainda nos primeiros dias após a Revolução, seguiam o Programa de Moncada e instituíram o fim do 
processo de despejo, o estabelecimento de preços máximos de vendas para terrenos urbanos e a redução de $50 \%$ nos preços dos aluguéis. Estas medidas, no entanto, não se mostraram suficientes para erradicação dos problemas urbanos, o que fez com que a Reforma Urbana assumisse uma resolução ainda mais radical: distribuir todas as moradias em regimes de aluguel para seus moradores sob a forma de propriedade pessoal privada. Na prática, isto significou que todos aqueles que moravam de aluguel tornaram-se donos de suas moradias sob as condições de pagamento facilitadas, e que, portanto, a enorme quantidade de trabalhadores sem moradia transformou-se em dona de suas habitações. A Reforma definiu o Estado como o principal responsável pela construção das habitações em detrimento das construtoras privadas, proibiu a compra de terrenos vazios e a posse de mais de uma moradia (com exceção da casa de veraneio), extinguiu o sistema hipotecário e transformou antigas construções signos do regime anterior em novos espaços, como é o caso da transformação das prisões em escolas (Trefftz, 2001).

A transformação da formação urbana e da condição de vida do trabalhador urbano a partir da Reforma Urbana foi inédita na América Latina. Identifica-se nela algumas medidas que buscaram a aproximação à proposta do homem natural martiano, ou seja, o pequeno proprietário individual, e a nacionalização do território cubano. Assim como acontecia no campo, nas cidades havia muitos terrenos, casarões e empresas de construção civil de origem estrangeira que se valiam das condições de exploração em Cuba para manter sua lucratividade e, em contrapartida, restringiam o acesso à terra aos próprios cubanos. É neste aspecto que a Revolução Cubana enxerga na propriedade privada da terra, e neste caso da moradia, uma saída para o problema imediato de controle estrangeiro do território nacional. Esta medida, no entanto, afasta-se das propostas elaborados pelo campo socialista para a questão habitacional, que versavam sobre a moradia de aluguel e a propriedade estatal do parque habitacional.

Consolidadas as políticas iniciais realizadas pelo governo revolucionário que visavam uma efetiva transformação do funcionamento da estrutura socioeconômica do país, passou-se à etapa de planificação central de longo prazo para que se buscasse alcançar um caminho de desenvolvimento sustentável e autônomo. Cabe lembrar que no momento em que o governo revolucionário começou a contar com uma situação de certa normalidade institucional, podendo voltar suas atenções a metas econômicas de longo prazo, já havia se optado por uma transição socialista, a qual induziu à nacionalização de virtualmente todo o complexo industrial e agropecuário existente no país. Deste modo, a planificação centralizada da 
produção material de Cuba pelo Partido Comunista permitiu que este moldasse o percurso de desenvolvimento social e econômico, de acordo com os valores previamente emergidos e consolidados nas lutas guerrilheiras, sob forte inspiração de José Martí.

Assim, os objetivos iniciais de longo prazo estabelecidos para a década de 1960 foram os de industrialização acelerada e diversificação da produção agrícola, para que, seguindo uma estratégia de substituição de importações, Cuba se tornasse soberana e se desvencilhasse dos empecilhos ao crescimento econômico impostos pelas relações desfavoráveis de comércio internacional. Se as transformações se efetivassem como planejado, a revolução estaria livre para avançar e assegurar os significativos ganhos de saúde, educação e cultura, pois contaria com sustentabilidade econômica para permanência do curso de melhoria social iniciado em 1959.

Perseguindo tais metas, o processo de transformação da estrutura produtiva iniciou-se pelo aumento da mecanização e da produtividade no complexo agropecuário, para que se reduzisse a importação de alimentos e para que o aumento da produção açucareira de exportação gerasse as divisas necessárias para importação de máquinas e insumos industriais. Ainda que o primeiro Plano Econômico tivesse previsto a expansão conjunta da produção açucareira (em menor velocidade) e das demais culturas agrícolas, na prática o estímulo à diversificação da agricultura resultou na redução absoluta da produção de açúcar, sendo substituídas as plantações de cana pelo cultivo de diversos alimentos de consumo interno. Este padrão foi corrigido após alguns anos e a exportação açucareira voltou a crescer, contudo, em um ritmo que não alcançou as ambiciosas metas do governo revolucionário.

No balanço econômico da década de 1960, pôde-se observar aumento generalizado da produtividade agropecuária, expansão da exportação açucareira, diversificação dos cultivos agrícolas, redução das importações de alimentos e crescimento das indústrias de bens de consumo duráveis e de capital. Contudo, o processo de industrialização não foi capaz de resolver os constrangimentos impostos pela balança de pagamentos do país, dado que frente à estrutura do complexo industrial cubano naquele momento, fazia-se necessário um elevado nível de importação de bens de capital e intermediários para que as transformações produtivas continuassem a ocorrer. (León, 2003)

A ênfase de Martí nos benefícios da formação humana proporcionada pelo trabalho agrícola baseiam-se no fato de que a interação entre homem e natureza seria elemento central na construção do homem natural. No entanto, cabe notar a atenção dada ao desenvolvimento 
das forças produtivas no setor industrial durante o curso dos trinta primeiros anos da Revolução Cubana. Esta pode ser entendida como uma resposta às políticas imperialistas dos países avançados, especialmente Estados Unidos, dado que as relações comerciais e financeiras globais se davam de maneira extremamente desfavorável aos países sem indústria nacional consolidada, de maneira que se fazia necessária para assegurar condições econômicas funcionais à busca por uma trajetória social soberana e popular. Desta feita, o chamado de Martí para o aproveitamento das potencialidades da agricultura cubana diversificada foi parcialmente obstaculizado pelo domínio do capital industrial em escala global no contexto histórico internacional vigente.

Assim, apesar de o primeiro Plano Econômico não ter possibilitado a efetiva autonomia de Cuba em relação ao cenário internacional, pode-se dizer que a estratégia perseguida esteve de acordo com traços fundamentais do pensamento de Martí no sentido de que a soberania nacional só poderia se completar em um contexto geopolítico em que as tratativas entre diferentes países se dessem em condições de igualdade de poder, como observado na primeira seção deste artigo. Para tanto, seguiu-se o objetivo de fortalecer uma estrutura produtiva industrializada e diversificada, que pudesse se contrapor às sanções e bloqueios econômicos articulados pelos EUA e seus aliados, com que Cuba teve que lidar durante a década e em momentos posteriores (Landau, 1989). No entanto, as disputas políticas e econômicas com os Estados Unidos ressaltam os limites da implantação das ideias martianas nas práticas socioeconômicas adotadas, de maneira que estas foram complementadas pela influência do pensamento marxiano e por forte planificação central nas estratégias perseguidas.

Sobre as estratégias de crescimento econômico na década de 1960 ressaltadas anteriormente, cabem ainda alguns comentários sobre adaptações das metas de planejamento. Inicialmente, o processo de industrialização foi pensado para se efetuar de maneira mais acelerada, para que o país reduzisse a necessidade de importação de máquinas e equipamentos, especialmente, dada a conjuntura de sanções e bloqueio econômico articulados pelos EUA. No entanto, o governo se deparou com uma situação de insuficiência de capital doméstico e externo para investimento em ritmo acelerado. Assim, em fins de 1963 o Partido Comunista Cubano realizou a primeira revisão da trajetória de desenvolvimento perseguida, cujo resultado foi o restabelecimento da importância relativa do complexo agropecuário, especialmente no que diz respeito à produção açucareira para exportação (Pérez Jr., 2017). A 
urgência de restabelecimento econômico postergou o projeto de industrialização acelerada, julgando-se que resultados mais rápidos poderiam ser alcançados pela mecanização generalizada da produção agropecuária, diversificação dos gêneros alimentícios de consumo interno (condizente com o objetivo geral de substituição de importações) e geração de divisas centrada na exportação de açúcar.

É importante lembrar que nos escritos em que Martí levantou questões relativas à estrutura produtiva cubana, diversas vezes chamou a atenção para as enormes possibilidades que as terras agricultáveis do país poderiam proporcionar ao processo de construção de um caminho de desenvolvimento democrático-popular. As exportações de diversos cultivos e a posição geográfica privilegiada do país nas rotas comerciais poderia ser a chave, segundo o autor, para o atingimento de relações de igualdade de poder entre Cuba e o comércio mundial. Enfatizava ainda que o trabalho rural vincularia o ser humano com a natureza, aspecto este fundamental na filosofia martiana. Assim, também aí o pensamento martiano foi combinado com a interpretação marxiana das principais lideranças revolucionárias, para que a soberania advogada por ambos os pensadores pudesse influenciar as soluções buscadas pela sociedade cubana.

Durante a primeira metade da década de 1970, Cuba melhorou significativamente seu padrão de inserção comercial e financeiro internacional. Isto se deu como resultado do retorno de condições favoráveis do ciclo de liquidez global, de cotações do açúcar bastante elevadas e da entrada do país no Conselho de Ajuda Mútua Econômica (CAME) em 1972. Esta organização, composta pelos países do bloco socialista da Europa Oriental durante a Guerra Fria, posteriormente ampliou sua área geográfica de atuação, incorporando as economias da Mongólia, Vietnã e Cuba.

A aproximação comercial de Cuba com os países do bloco permitiu a garantia de mercado consumidor para a produção açucareira do país a preços subsidiados. Além disto, as relações entre os países do CAME pressupunham coordenação entre as estratégias de planejamento central domésticas, de maneira que os investimentos realizados em cada país fossem complementares, para benefício de todo o bloco socialista no médio e longo prazos. Deste modo, a exportação açucareira cubana passou a financiar a importação de máquinas e equipamentos fornecidos pela URSS a preços que visavam possibilitar o desenvolvimento econômico sustentável de ambas as regiões. 
Mesmo antes da entrada oficial de Cuba no CAME, o comércio do país já havia se deslocado significativamente do bloco Ocidental para o Oriental desde a Revolução de 1959, permanecendo algumas importações indispensáveis de bens de capital e intermediários de economias capitalistas e exportação de uma pequena parcela da produção agropecuária. Podese observar, portanto, que as relações econômicas de Cuba desde a Revolução, foram guiadas, dentro do possível, pelo desenvolvimento de relações de vantagens mútuas e de cooperação internacional, de maneira que o ideal martiano de equilíbrio del mundo foi aproximado pela realidade dos países socialistas.

É interessante observar, portanto, que os valores martianos de nacionalismo e soberania impactaram de maneira mais forte os acontecimentos históricos revolucionários, em detrimento dos aspectos econômicos de corte mais liberal de seu pensamento socioeconômico. Neste sentido, os esforços pela efetiva emancipação da sociedade cubana e pela soberania nacional nortearam as estratégias adotadas, ainda que no plano individual todos estivessem sujeitos às determinações de planificação central do PCC, necessárias especialmente naquele momento de forte tensão entre os dois polos geopolíticos mundiais.

Tendo estabelecido a estratégia de inserção e articulação externa, o governo revolucionário cubano voltou suas atenções à planificação de longo prazo das forças produtivas internas. Assim, em dezembro de 1975 se reúnem amplo número de delegados no I Congresso do Partido Comunista Cubano para debate de todos os principais aspectos relativos ao desenvolvimento socioeconômico nacional. Ficam aí estabelecidas, entre outras medidas, a criação da primeira constituição socialista do país, a implantação do Sistema de Planejamento e Direção Econômica (SPDE) e a reorientação do crescimento econômico centrado no setor industrial.

A constituição socialista foi instituída após amplo processo de consulta e sugestões de diversas instâncias da sociedade civil, de maneira que não foi imposta unilateralmente pelos membros da burocracia central. Além de explicitar oficialmente os valores que vinham guiando os objetivos sociais de longo prazo perseguidos em Cuba, a constituição afirmou a igualdade individual no que diz respeito à raça, gênero e religião, no melhor espírito martiano. No que tange à contabilidade do setor público, o Sistema de Planejamento e Direção Econômica (SPDE) representou a importação de mecanismos de controle utilizados em países da Europa Oriental, adaptados, em algum grau, às particularidades da situação cubana. A 
opção adotada se deu pelo benefício do auxílio técnico da União Soviética com que Cuba poderia contar, dada a padronização dos processos administrativos.

Em um de seus escritos mais conhecidos, Nossa América, Martí enfatizou a necessidade da busca de soluções intelectuais originais para os problemas específicos de nações cujo processo de desenvolvimento social, cultural, político e econômico se deu de maneira bastante distinta daquela que vigorou nos países avançados. Portanto, a importação de um sistema de planejamento e direção forjado com o objetivo de resolver problemas de outra natureza em outra situação histórica contraria o espírito martiano de soberania intelectual e cultural. Se bem que o sistema tenha sido adaptado à realidade cubana, sua origem se deu em contexto totalmente distinto na União Soviética.

Em relação à estratégia de desenvolvimento econômico, o I Congresso do Partido Comunista Cubano ressaltou a opção por um crescimento industrial mais acelerado, dada a conjuntura internacional mais favorável e as transformações na inserção internacional do país. Desta feita, buscou-se orientar a produção industrial em direção aos bens de capital, especialmente àqueles utilizados pelos complexos produtivos agropecuários (principalmente o setor açucareiro exportador) e aos bens de consumo durável para consumo doméstico, objetivos estes condizentes com a estratégia mais geral de substituição de importações.

As elevadas taxas de crescimento da indústria de 1976 a 1986, além de terem reduzido a dependência externa da economia cubana, proporcionaram aumento considerável do padrão de vida material do povo cubano, que teve seu acesso a bens alimentícios, têxteis e duráveis facilitado. Portanto, a continuação e o aprofundamento do processo de diversificação produtiva, como recomendado nos escritos de Martí, e de industrialização representaram mais um movimento em direção à construção de uma sociedade autônoma, ao passo que a melhoria geral do padrão de vida confirmou o caráter verdadeiramente social da Revolução.

Cabe observar que no período analisado (1976-86) ganharam força as categorias mercantis capitalistas como o lucro, a rentabilidade, o preço, o salário e a eficiência produtiva na organização da esfera material da sociedade cubana, reforçando a tendência que se observava anteriormente. Sendo assim, o homem natural martiano se tornava mais difícil de ser alcançado, à medida que a racionalidade da civilização ocidental voltava a aparecer e permear a construção social do país. Na segunda metade dos anos 1980, a União Soviética entrava na perestroika enquanto os países do bloco socialista passavam por processos semelhantes de descentralização política e econômica e de fortalecimento dos mercados 
privados. Em Cuba, ao contrário, neste mesmo período a campanha de retificação de erros iniciada em 1986 visava reafirmar os valores socialistas revolucionários na organização da sociedade, corrigindo a tendência de fortalecimento excessivo do setor privado que teria ocorrido de 1976 a 1985.

A estratégia de desenvolvimento adotada, longe de ter emergido apenas de considerações ideológicas e morais, buscou enfrentar os problemas reais engendrados pelos déficits doméstico e externo do governo cubano (Eckstein, 1990). Assim, medidas de austeridade foram adotadas, como o corte de subsídios de energia elétrica e o aumento das tarifas de ônibus, de maneira que o padrão de vida material da população decaiu nos anos imediatamente posteriores a 1986. Em relação ao setor externo, o Partido Comunista decretou a proibição dos mercados livres no setor agrícola, aumentando o controle do Estado sobre os principais gêneros alimentícios produzidos, que antes se destinavam primeiramente ao consumo privado.

Sem desconsiderar a importância destas reformas setoriais, deve-se ter em mente que o principal foco da campanha de retificação de erros recaiu sobre o Sistema de Planejamento e Direção Econômica (SPDE), mecanismo de contabilidade pública que teria gerado excessiva descentralização política das decisões fundamentais e dotado os gerentes de empresas públicas de poderes que dificultavam a execução dos objetivos socialmente planificados (Pérez-López, 1990). A administração da economia pelo SPDE passou a dar ênfase ao cálculo econômico empresarial, em critérios de lucratividade para guia das decisões das empresas públicas e a buscar atrelar os salários à produtividade. Gradualmente, a acumulação privada foi tendo maior permissividade, dado o processo em curso de fortalecimento das instituições mercantis na lógica de organização da sociedade cubana.

Sem extinguir o cálculo econômico e os incentivos materiais à produção, o Partido Comunista atentou-se para a importância de restaurar os incentivos morais e o comprometimento da população com os valores sociais revolucionários, resgatando a tradição nacional de lutas emancipadoras e de construção de uma sociedade soberana, popular e autóctone. Ainda que a conjuntura internacional não tenha possibilitado a reversão dos problemas de balanço de pagamento, e que o orçamento doméstico tenha permanecido com resultados deficitários, o processo de retificação de erros permitiu à sociedade cubana o resgate de seus valores históricos e a sobrevivência do socialismo no país em um contexto de transformação da geopolítica global e da reorganização do padrão de acumulação, 
evidenciado a opção por um socialismo autóctone. Assim, as mudanças políticas da retificação acentuam mais uma vez a busca do governo e da sociedade cubana por equilibrar de maneira complementar proposições autóctones com influências internacionais na construção de uma trajetória soberana nos âmbitos social e individual. Os dois intelectuais que continuaram a exercer maior influência nesta construção histórica do socialismo nacionalpopular cubano continuaram sendo José Martí e Karl Marx.

Em seus discursos nos anos em que esta reestruturação administrativa se deu em Cuba, Fidel Castro evocou José Martí diversas vezes, para afirmar a necessidade de que o país percorresse um caminho de desenvolvimento soberano e original, respeitando suas raízes históricas e buscando aprofundar os valores sociais que deveriam permear a construção de uma democracia verdadeiramente popular.

\section{Considerações Finais}

Este artigo teve por objetivo analisar os desdobramentos político-econômicos da sociedade cubana nos primeiros trinta anos pós-Revolução de 1959, a partir da influência do pensamento de José Martí.

$\mathrm{Na}$ primeira parte, destacaram-se alguns aspectos fundamentais que nortearam as recomendações de política deste autor, emergidos de suas vivências no exílio em diversos países e do contato que teve com diversas vertentes teóricas que iriam subsidiar seu projeto de emancipação individual e social idealizado para Nuestra América. Deve-se ressaltar a importância no pensamento de Martí da busca pela construção de uma sociedade baseada no amor e verdadeiramente soberana e democrática, capaz de proporcionar a todos os cidadãos condições materiais adequadas. Para tanto, faz-se elementar, a remuneração justa do trabalho e a liberdade para que os indivíduos possam atingir todas as suas potencialidades, independentemente de classe social, raça e origem.

De maneira geral, as transformações socioeconômicas ocorridas após a Revolução Cubana deixaram clara a influência de Martí nas lideranças do governo como guia da construção da nova sociedade. Martí é convocado a ocupar o posto de patrono da Revolução Cubana por suas contribuições à formulação teórica sobre o imperialismo, dado o caráter expressamente anti-imperialista da Revolução Cubana. Para além de seu papel simbólico, é possível depreender suas contribuições teóricas em muitas passagens. 
A primeira delas pode ser observada na primeira Lei de Reforma Agrária, promulgada em 1959, como um passo fundamental no combate ao domínio neocolonial estadunidense em relação à estrutura latifundiária do país. Desta feita, Cuba deu assim seu primeiro grande passo na construção de sua soberania nacional. Ao mesmo tempo, como defendido por Martí, os trabalhadores agrícolas passaram a ter direito à posse das pequenas propriedades que cultivavam, fortalecendo os laços do homem com a natureza e proporcionando condições adequadas de vida e emancipação do trabalhador agrícola. Ainda em relação à agricultura, buscou-se diversificar a produção para garantir a soberania alimentar e reduzir as importações de alimentos em Cuba, estratégia está enfatizada por Martí em suas recomendações de política econômica.

Ainda que nos primeiros anos após a revolução se tenha buscado por uma maior conciliação de interesses na estratégia política nacional, as ofensivas contrarrevolucionárias domésticas e externas impediram que se insistisse neste caminho. Deste modo, em última instância, toda propriedade de terra passou para as mãos do Estado (ainda que permanecesse a posse de pequenos lotes de terra pelos agricultores que os cultivavam em um regime de dupla propriedade), extinguindo a exploração capitalista privada no setor.

A mesma consideração pode ser feita sobre a reforma urbana: enquanto as experiências socialistas e suas produções teóricas sobre o tema incentivaram a adoção de um modelo de habitação pública baseada na propriedade estatal e posse familiar, o modelo seguido por Cuba priorizou a propriedade pessoal privada, com influência do pensamento martiano, que via nesta forma de propriedade a liberação do trabalhador, e como garantia em um contexto de acirramento da contrarrevolução. Mais um vez, a Revolução Cubana seguiu, portanto, suas demandas e agendas internas, diferenciando-se das práticas socialistas já construídas em outras experiências reais.

Consolidado o caráter socialista tomado pela Revolução, na década de 1960 buscou-se o desenvolvimento das forças produtivas, em especial da indústria do país. Em seus escritos, Martí não aborda a necessidade de desenvolvimento da indústria para o atingimento da soberania dos territórios latino-americanos, muito em função da conjuntura diversa encontrada em fins do século XIX. Contudo, a estratégia do desenvolvimento industrial cubano foi condizente com os ideais do pensador, especialmente quando temos em mente o conceito de equilíbrio del mundo e o fortalecimento da posição geopolítica de Cuba engendrada pela diversificação e mecanização de suas estruturas produtivas. 
O I Congresso do Partido Comunista Cubano, em dezembro de 1975, deu continuidade à estratégia de diversificação produtiva e industrialização, reforçando a busca pela soberania nacional cubana e pela melhoria generalizada da condição material de vida da população. As discussões realizadas neste encontro atualizaram os mecanismos de representação democrática do país e estabeleceram a primeira Constituição socialista desde a Revolução, guiando-se pelo espírito martiano de emancipação individual independente de raça, gênero e religião.

Ainda que o pensador continuasse sendo uma das principais inspirações teóricas do governo revolucionário, a implantação do Sistema de Planejamento e Direção Econômica (SPDE), importado da União Soviética, colocou categorias mercantis no núcleo do funcionamento da economia cubana. Assim, Cuba se distanciou do ideal de homem natural martiano e se aproximou do padrão de civilização ocidental emergido no continente europeu. Este distanciamento do pensamento martiano e a aproximação com o sistema soviético de planificação e organização institucional foram reconhecidos pelas lideranças revolucionárias, quando se deu início à campanha de retificação de erros em 1986. Através desta, reconheceram-se as consequências da perda de autonomia econômica e de identidade cultural e buscaram-se reafirmar os ideais democráticos construídos em Cuba em cem anos de luta pela emancipação do indivíduo e da sociedade e a busca por um padrão civilizatório autóctone. Não por acaso, algumas reformas descentralizadoras visando tais emancipações foram implementadas neste momento, assim como foi reformulado o sistema de representatividade política, buscando recuperar a institucionalidade democrática de anos anteriores.

Desta feita, se pôde perceber, ao longo da análise realizada no presente artigo, que o pensamento martiano exerceu forte influência sobre o movimento revolucionário ao pautar a busca pela soberania nacional, mesmo que em diversos momentos tenha sido necessário afastar-se deles para responder a necessidades históricas específicas. Os aportes de seu pensamento estão presentes tanto nas políticas públicas, como mostramos, quanto nos discursos de Fidel e nas formações das narrativas teóricas nacionais. São majoritariamente estes aportes que conferem particularidade à Revolução Cubana e que a diferenciam das outras experiências socialistas.

\section{Referencias Bibliográficas}


ACANDA, Jorge L. Fernando Buey y la Recuperación del marxismo crítico en Cuba. In: TORRES, A. PASUCH, Márcia Cristina M. Encontros con Paco Buey. Editora UFMT: Cuiabá, 2013.

ARNAL, Salvador L. Entrevista a Jorge Luis Acanda. Papeles de relaciones ecosociales y cambios globales, $\mathrm{n}^{\circ} 126,2014$.

BARRERAS, Dairy; LÓPEZ, Olga; MÉNDEZ, José. GUITIÉRREZ, Robin. Carlos Marx y Rosé Martí: coincidencias en las concepciones sociopolíticas y culturales. Humanidades Médicas, $\mathrm{n}^{\circ} 18, \mathrm{v} 3,2018$.

CANO, W. Soberania e Política Econômica na América Latina. Editora Unesp. São Paulo, 2000 .

CASTRO RUZ, Fidel. La historia me absolverá. 1964.

. The Declarations of Havana. Verso Books, 2018.

. La historia me absolverá. Ediciones Colihue SRL, 1993.

ECKSTEIN, Susan. The Rectification of Errors or the Errors of the Rectification Process in Cuba? Cuban Studies, p. 67-85, 1990.

LANDAU, S. Notes on the Cuban Revolution. The Socialist Register, 1989.

LEÓN, A. S. Breve Historia de La Revolución Cubana (1959 - 2000). Editorial Ciencias Sociales. La Habana, 2003.

MARTÍ, José. José Marti: Obras Completas. Editorial de Ciencias Sociales. La Habana, 1991.

. Mi raza. Patria, Nueva York, v. 16, p. 299, 1893.

. Nossa América. Editora Universidade de Brasília. Brasília, 2011.

MARTIN, Juan L. La investigación social en Cuba (1959 - 1997). Temas, nº 16- 17, 1999.

MOLINA, E. M. Devenir Del Modelo Económico Socialista. Editorial de Ciencias Sociales. La Habana, 2016.

NAVARRO, José C. El desafío del yugo y la estrella. La Habana: SI-MAR SA, 2000.

PÁZ, J. V. “A Revolução Agrária Cubana: conquistas e desafios”. Estudos Avançados. v.72, n. 25,2011

PÉREZ-LÓPEZ; J. F. "Rectification At Three: Impact on the Cuban Economy". Studies in Comparative International Development, Fall , Vol. 25, no. 3, 1990

PÉREZ Jr. L. A. La estructura de la Historia de Cuba: significados y propósitos del passado. Editorial de Ciencias Sociales. La Habana, 2017. 
RODRIGUEZ, J. L. Estratégia del Desarrollo Económico em Cuba. Editorial de Ciencias Sociales. La Habana, 1990.

RODRIGUES JÚNIOR, Mao. A revolução cubana e a questão nacional (1868-1963). Núcleo de Estudos do capital: 2007.

SANDOVAL, Orieta A; HERNANDES, Afredo A A. Las ciências sociales em la academia de ciências em Cuba (1962 -1981). Tiempos de America, nº 9, 2002.

SANTOS, Fabio Luis Barbosa dos. Origens do pensamento e da política radical na América Latina: um estudo comparativo entre José Martí, Juan B. Justo e Ricardo Flores Magón. 2011. Tese de Doutorado (História Econômica). Universidade de São Paulo.

SUCHILICK, Jaime. The political ideology of José Martí. Caribbean Studies. Vol 6. No 1, 1996.

TREFFTZ, Erich. "50 años de reforma Urbana em Cuba: em el aniversario del cambio de paradigma”. Revista INVI. v 26, nº 72. Agosto de 2001.

TRETO, Carlos A. La ciencia política en Cuba: del estancamiento a la renovación (1980 2005). Revista de Ciencia Política de Santiago, v. 25, n. 1, 2005.

\title{
Os Primeiros Trinta Anos da Revolução Cubana à Luz do Pensamento Martiano
}

\begin{abstract}
Resumo
José Martí é considerado o patrono da Revolução Cubana por sua contribuição intelectual e militância política à independência de Cuba. Inscrito na tradição do pensamento cubano preocupado com a independência nacional e dialogando com pensadores do liberalismo europeu e norte-americano, Martí repensa a condição de colônia da ilha e propõe soluções autóctones com o intuito de viabilizar a soberania nacional, muitas das quais foram referenciadas no discurso e nas políticas do movimento revolucionário que destituiu o governo Batista em 1959. Apesar de Martí representar incontestavelmente o apóstolo da Revolução, a gradual perda de influência da teoria martiana nos debates acadêmicos frente a ascensão do materialismo dialético durante os primeiros trinta anos do governo revolucionário levou alguns analistas a sugerirem a diminuição de sua influência política. O objetivo principal deste trabalho é de identificar a influência do pensamento de Martí na condução dos 30 primeiros anos da Revolução Cubana e pontuar as interações desta com os desdobramentos políticos, sociais e econômicos tomados pela Revolução Cubana. Para cumprir este objetivo, recuperam-se ao longo do texto alguns traços do pensamento de Martí e busca-se fazer emergir suas influências na formulação da Reforma Agrária, Urbana e do planejamento econômico ao longo deste período.
\end{abstract}

Palavras-chave: José Martí, Revolução Cubana, história do pensamento econômico, pensamento filosófico cubano.

\section{Una Mirada a los Primeros Treinta Años de la Revolución Cubana desde el Pensamiento Martiano}

\section{Resumen}

Revista de Estudos e Pesquisas sobre as Américas V.13 N.3 2019 ISSN: 1984-1639 
José Martí es considerado el apóstol de la Revolución Cubana por su contribución intelectual y militancia política a la independencia de Cuba. Parte de la tradición académica cubana interesada en la revolución nacional y en debate con los pensadores del liberalismo europeo y norteamericano, Martí elabora su formulación para comprender la condición de colonia de la isla y propone soluciones autóctonas para lograr la soberanía nacional. Muchas de ellas fueran parte de los discursos y de las políticas del movimiento revolucionarios que destituyo Batista en 1959. Pero, aunque se pueda reconocer Martí el apóstol de la revolución, la pérdida de influencia de su teoría y el crecimiento del materialismo dialéctico en los campos académicos en los treinta anos iniciales de la revolución, hicieran algunos investigadores reclamar la disminución de su influencia política. El objetivo de este artículo es identificar la influencia del pensamiento martiano en los treinta años iniciales de la Revolución Cubana y revelar sus interacciones con los desarrollos políticos, sociales y económicos del gobierno revolucionario. Para cumplirlo, presentaremos algunas huellas del pensamiento martiano y expondremos sus influencias en la formulación de la Reforma Agraria, Urbana y la planificación económica durante este período.

Palabras-clave: José Martí, Revolución Cubana, historia del pensamiento económico, pensamiento filosófico cubano.

\title{
A Review First Thirty Years of the Cuban Revolution From the Marti's Thought Perspective
}

\begin{abstract}
Jose Marti is considered the patron of the Cuban revolution for his intellectual and political militancy contribution. Descendant of the Cuban academic thought worried about the national independency and in dialog with the European and liberal traditions, Martí rethink the colony position of the island and propose autochthonous solutions to achieve the national sovereignty, which were referenced on the speeches and policies by the revolutionary leadership, who defeated the Batista government in 1959. Despite the recognition of Martí as the Apostol of the revolution, on the first 30 years of the revolution government, the gradual loss of influence of his thought, in comparison of the rise of the dialectical materialism, led some analysts to suggest the decrease of his political influence. The main objective of this paper is to identify the influence of José Martí's thought on the conduction of the first 30 years of the Cuban revolution and evaluate its interaction with de political, social and economic developments. To accomplish this task, some traces of Marti's thought will be recovered and its articulations with the formulations of the Agrarian and Urban Reform and economic planning will be highlighted.
\end{abstract}

Keywords: José Martí, Cuban Revolution, history of economic thought, Cuban philosophical thinking. 